Research Paper

\title{
Effect of exopolysaccharides from cariogenic bacteria on human gingival fibroblasts
}

\author{
Anna K. Szkaradkiewicz-Karpińska1 ${ }^{1}$ Andrzej Szkaradkiewicz ${ }^{\circledR}$ \\ 1. Department of Preclinical Conservative Dentistry and Preclinical Endodontics, University of Medical Sciences, 60-812 Poznań, Poland. \\ 2. Institute of Health and Physical Culture, State Higher Vocational School, 64-100 Leszno, Poland. \\ $\square$ Corresponding author: Professor Andrzej Szkaradkiewicz, Institute of Health and Physical Culture, State Higher Vocational School, 64-100 Leszno, \\ Mickiewicza 5 Street, Poland. E-mail: szkaradkiewicza@poczta.onet.pl. \\ (c) The author(s). This is an open access article distributed under the terms of the Creative Commons Attribution License (https://creativecommons.org/licenses/by/4.0/). \\ See http://ivyspring.com/terms for full terms and conditions.
}

Received: 2020.12.16; Accepted: 2021.04.19; Published: 2021.05.13

\begin{abstract}
Bacterial biofilm (dental plaque) plays a key role in caries etiopathogenesis and chronic periodontitis in humans. Dental plaque formation is determined by exopolysaccharides (EPSs) produced by cariogenic and periopathogenic bacteria. The most frequent cariogenic bacteria include oral streptococci (in particular S. mutans) and lactobacilli (most frequently L. acidophilus). In turn, the dominant periopathogen in periodontitis is Porphyromonas gingivalis. Development of dental caries is often accompanied with gingivitis constituting the mildest form of periodontal disease. Basic cellular components of the gingiva tissue are fibroblasts the damage of which determines the progression of chronic periodontitis. Due to insufficient knowledge of the direct effect of dental plaque on metabolic activity of the fibroblasts, this work analyses the effect of EPSs produced by $S$. mutans and $L$. acidophilus strains $\left(\mathrm{H}_{2} \mathrm{O}_{2}\right.$-producing and $\mathrm{H}_{2} \mathrm{O}_{2}$-not producing) on ATP levels in human gingival fibroblasts (HGF-l) and their viability. EPSs produced in 48-hours bacterial cultures were isolated by precipitation method and quantitatively determined by phenol - sulphuric acid assay. ATP levels in HGF-1 were evaluated using a luminescence test, and cell viability was estimated using fluorescence test. The tests have proven that EPS from $S$. mutans did not affect the levels of ATP in HGF-1. Whereas EPS derived from L. acidophilus strains, irrespective of the tested strain, significantly increased ATP levels in HGF-1. The analysed EPSs did not affect the viability of cells. The tests presented in this work show that EPSs from cariogenic bacteria have no cytotoxic effect on HGF-1. At the same time, the results provide new data indicating that EPSs from selected oral lactobacilli may have stimulating effect on the synthesis of ATP in gingival fibroblasts which increases their energetic potential and takes a protective effect.
\end{abstract}

Key words: dental caries, Streptococcus mutans, Lactobacillus acidophilus, exopolysaccharides, ATP, gingivitis

\section{Introduction}

It is already known that the so called cariogenic bacteria, mainly oral streptococci, especially Streptococcus mutans and lactobacilli, most frequently Lactobacillus acidophilus, played a key role in etiopathogenesis in dental caries $[1,2,3]$. These bacteria demonstrate intensive acidogenicity and acid tolerance $[2,4]$. Moreover, they have the ability to produce extracellular polysaccharides (EPS) which allow accumulation of bacteria on the surface of tooth enamel and creation of dental plaque (cariogenic biofilm), in the consequence of which tooth decay develops $[5,6,7,8]$. On the other hand, dental plaque accumulation on teeth adjacent to the gingiva induces gingivitis, which constitutes the mildest form of periodontal disease and affects $50-90 \%$ of adults worldwide [9]. Dental plaque associated with periodontal disease is built of anaerobic bacteria (the so called periopathogens), and the dominant periopathogen is Porphyromonas gingivalis [10, 11]. Previous studies have proven that extracellular products of selective periopathogens reduce the synthesis of adenosine triphosphate (ATP) in gingival fibroblasts [12]. Contrary to those results, it was determined that extracellular products of selected Lactobacillus acidophilus strains cultures may stimulate ATP synthesis in gingival fibroblasts [12]. However, 
the tests performed concerned only supernatants obtained from a 24-hours bacteria culture. Considering the above data, the purpose of this work was to analyse the effect of EPSs produced by $S$. mutans and L. acidophilus on ATP levels in human gingival fibroblasts.

\section{Materials and Methods}

\section{Bacterial strains and culture conditions}

The following bacterial strains were used: Streptococcus mutans (ATCC 25175) and 2 strains of Lactobacillus acidophilus - MT $\left(\mathrm{H}_{2} \mathrm{O}_{2}\right.$-producing) and VF $\left(\mathrm{H}_{2} \mathrm{O}_{2}\right.$-not producing). S. mutans was cultured on Schaedler agar (Sigma, MO, USA) with 5\% red sheep cells and incubated for 48 hours at $37^{\circ} \mathrm{C}$ in anaerobic conditions. L. acidophilus strains were isolated in Biochemistry Research Laboratory Ohio University, Athens, USA from unstimulated whole saliva of healthy adults and cultured on Rogosa agar (Sigma, $\mathrm{MO}, \mathrm{USA})$ at $37{ }^{\circ} \mathrm{C}$ for 48 hours in anaerobic conditions. Selected strains were identified using API CHL (bioMerieux, SA, France). The capacity of hydrogen peroxide production among Lactobacillus strains was defined in culture of the obtained isolates in the presence of $5 \% \mathrm{CO}_{2}$ at the temperature of $37^{\circ} \mathrm{C}$ for 48 hours in a differentiating medium, TMB Plus agar (Sigma, MO, USA), according to Rabe and Hillier [13]. At the same time, $\mathrm{H}_{2} \mathrm{O}_{2}$-producing L. acidophilus strain (ATCC 4356) constituted positive control for the tests. Development of an altered colour of the growing colonies (appearance of a blue colour) indicated the production of hydrogen peroxide (Figure 1).

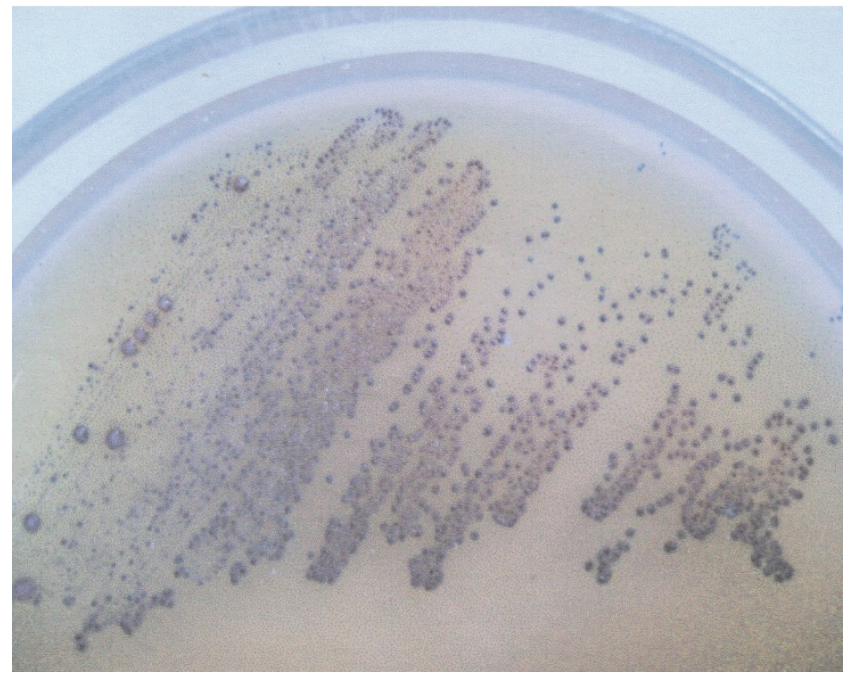

Figure 1. $\mathrm{H}_{2} \mathrm{O}_{2}$-producing Lactobacillus acidophilus strain (note the blue color of grown-up colonies on TMB-Plus agar in a $48 \mathrm{~h}$ aerobic culture with supplementation of $5 \% \mathrm{CO}_{2}$, at $37^{\circ} \mathrm{C}$.

\section{EPS production and isolation}

Bacteria S. mutans and L. acidophilus isolates were inoculated in tryptic soy broth (TSB; Sigma, MO, USA) and incubated at $37{ }^{\circ} \mathrm{C}$ for $48 \mathrm{~h}$ in anaerobic conditions. Subsequently the cultures were centrifuged at $8000 \times \mathrm{g}$ at $4{ }^{\circ} \mathrm{C}$ for $10 \mathrm{~min}$. The supernatants of bacterial cells were collected. Precipitation of EPS from each supernatant was provided using cold $96 \%$ ethanol $\left(-20^{\circ} \mathrm{C}, 1: 2 \mathrm{v} / \mathrm{v}\right)$ stored overnight at $4{ }^{\circ} \mathrm{C}$. Samples were centrifuged at $4{ }^{\circ} \mathrm{C}, 8000 \times \mathrm{g}$ for $10 \mathrm{~min}$. Precipitates were collected, dissolved in distilled water, mixed and re-precipitated under the same conditions $[14,15]$. Subsequently EPS samples were centrifuged at $4{ }^{\circ} \mathrm{C}, 8000 \times \mathrm{g}$ for $10 \mathrm{~min}$, mixed with PBS, digested with proteinase $\mathrm{K}\left(37^{\circ} \mathrm{C}\right.$ for $1 \mathrm{~h}$ ) and dialysed against distilled water at $4{ }^{\circ} \mathrm{C}$ for 48 $\mathrm{h}$. The EPS samples were stored at $-20^{\circ} \mathrm{C}$. Total carbohydrates number was measured colourimetrically by phenol-sulfuric acid method in 96-well microplates [16]. Absorbance level (A) was read at $490 \mathrm{~nm}$ using microplate reader.

\section{Cell cultures}

Human gingival fibroblasts (HGF-1, ATCC CRL-2014) were cultured in Dulbecco's Modified Eagle Medium (DMEM; Gibco, NY, USA) supplemented with $10 \%$ heat-inactivated foetal bovine serum (FBS; Gibco, NY, USA) and with antibiotics (penicillin $100 \mathrm{U} / \mathrm{ml}$ and streptomycin 20 $\mathrm{mg} / \mathrm{ml}$; Sigma) at $37{ }^{\circ} \mathrm{C}$ in humidified $5 \% \mathrm{CO}_{2}$ incubator. The media were replaced three times a week. Two hours before the experiments of testing ATP levels in fibroblasts, cell monolayers were washed and fresh medium was added.

\section{ATP assay}

ATP content of gingival fibroblasts was evaluated using a luminescence test (CellTiter-Glo Luminescent Cell Viability Assay; Promega). The studies in three repetitions, were conducted in culture medium in the presence of a buffered physiological saline $\left(50 \mu \mathrm{l}\right.$ PBS $/ 0.5 \times 10^{6}$ HGF- 1 cells $/ 450 \mu$ l culture medium) - the control, and in the presence of each isolated EPS (50 $\mu$ l EPS/ $0.5 \times 10^{6} \mathrm{HGF}-1$ cells $\left./ 450 \mu \mathrm{l}\right)$. In preliminary experiments it was confirmed that EPS in concentration of $1 \mathrm{mg} / \mathrm{ml}$ DMEM was a maximum dose for ATP levels alterations in gingival fibroblasts. The prepared cells were incubated for 24 hours in humidified $5 \% \mathrm{CO}_{2}$ incubator at $37^{\circ} \mathrm{C}$. Then, the cells were rinsed with the buffered physiological saline (PBS) and tested for ATP according to the Promega protocol (http.//:promega.com). The results were read using a luminometer (GloMax, Promega). The light emitted in the presence of ATP was quantitated in relative light units (RLU). The intensity of emitted 
light quants was directly related to ATP content in the tested sample.

\section{Viability of gingival fibroblasts}

The viability testing in HGF-1 gingival fibroblasts took advantage of the Live/Dead Viability/Cytotoxicity Kit (Invitrogen, USA) fluorescence test. The studies were conducted in Lab-Tek Chamber Slide (Nunc) culture chambers in

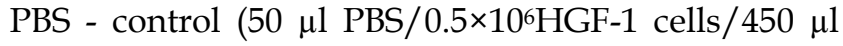
culture medium), or in the presence of each EPS obtained from cultures of selected bacterial strains (50 $\mu 1$ EPS/0.5×106 HGF-1 cells/450 $\mu$ l culture medium). The medium involved DMEM (Gibco, NY, USA) solution, enriched with $10 \%$ foetal bovine serum (FBS, Gibco, NY, USA). The prepared cells were incubated for 24 hours in humidified $5 \% \mathrm{CO}_{2}$ incubator at the temperature of $37^{\circ} \mathrm{C}$. Subsequently, the cells were washed in the culture medium and tested for their viability. The readouts were made at zero time and following 6, 12, 18 and 24 hours, using a Nikon Eclipse E200 fluorescence microscope (magnification of $1000 \times$ ).

\section{Statistical analysis}

Results obtained in the tests were analysed using the computer software PQStat 1.8.0. Data distribution normality was controlled with Shapiro-Wilk test. For the comparative analysis of ATP levels alterations in time ANOVA test was applied for repeated measures. The comparison of respective results between the tested groups was made on the basis of contrasts analysis for One-Way ANOVA. In every test, hypotheses were verified at the significance level of $p=0.05$. Data are presented as the mean \pm standard deviation (sd).

\section{Results}

\section{ATP levels in gingival fibroblasts (HGF-1)}

The mean ATP level in gingival fibroblast cultures (control) at zero time amounted to $4.68 \pm 0.19$ million RLU. The result was not statistically different from the mean ATP values determined within the next $6,12,18$ or 24 hours $(p>0.05)$. The results are shown in Figure 2.

\section{EPSs of Streptococcus mutans activity}

EPSs of Streptococcus mutans (ATCC 25175) did not change ATP levels in gingival fibroblasts $(p>0.05)$ The mean ATP level in the presence of EPSs after 6 hours of incubation was $4.82 \pm 0.34$ and within 24 hours corresponded to the control values (Figure 2).

\section{EPS $_{\mathrm{s}}$ of oral lactobacilli activity}

EPSs produced by $L$. acidophilus strains significantly increased ATP levels in gingival fibroblasts as compared with control cultures $(p<0.001)$. The mean ATP levels in fibroblasts cultures in the presence of EPSs of $\mathrm{H}_{2} \mathrm{O}_{2}$-producing $L$. acidophilus and $\mathrm{H}_{2} \mathrm{O}_{2}$-not producing L. acidophilus already after 6 hours amounted to $7.89 \pm 0.93$ million RLU and 7.78 \pm 0.94 million RLU respectively, whereas those values, at all times of the test were not statistically different $(p>0.05)$. The induced effect of EPSs persisted for a period of $24 \mathrm{~h}$ was presented in Figure 3.

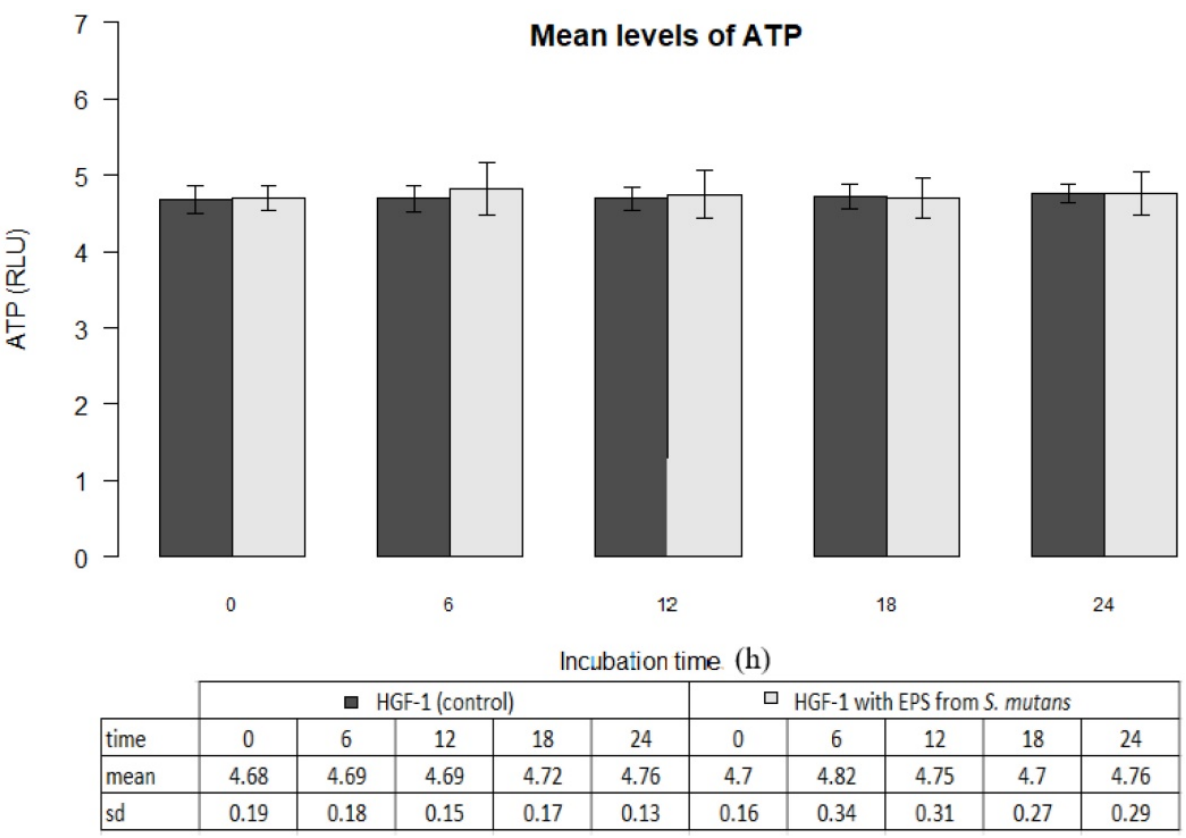

Figure 2. Mean levels of ATP (luminescence in millions of RLU) in cultures of gingival fibroblasts (HGF-1) at zero time and following 6, 12,18 or $24 \mathrm{~h}$ incubation with EPS from S.mutans. 


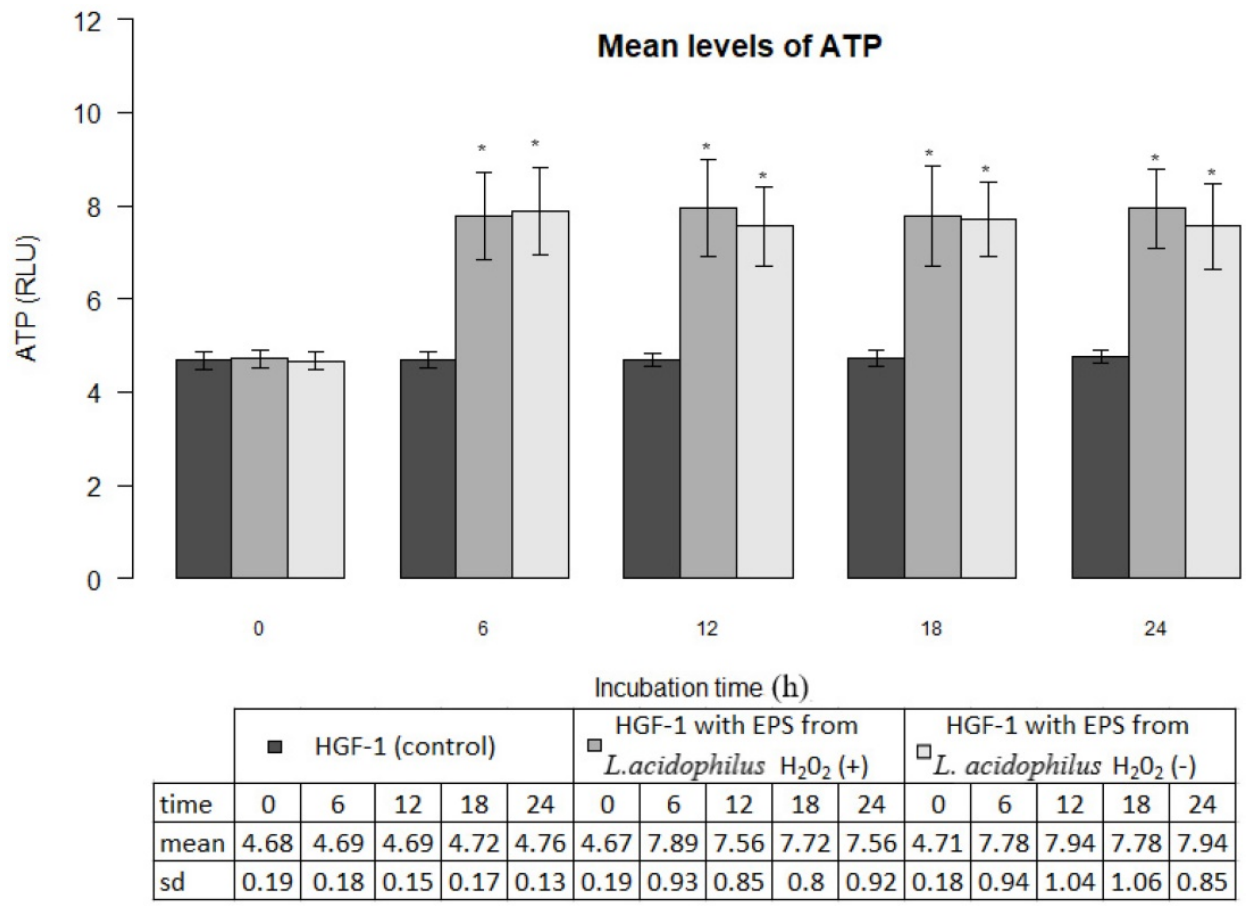

Figure 3. Mean levels of ATP (luminescence in millions of RLU) in cultures of gingival fibroblasts (HGF-1) at zero time and following $6,12,18$ or $24 \mathrm{~h}$ incubation with EPS from L. acidophilus $\mathrm{H}_{2} \mathrm{O}_{2}(+)$ or L.acidophilus $\mathrm{H}_{2} \mathrm{O}_{2}(-)$; * marked significant difference compared to zero time.

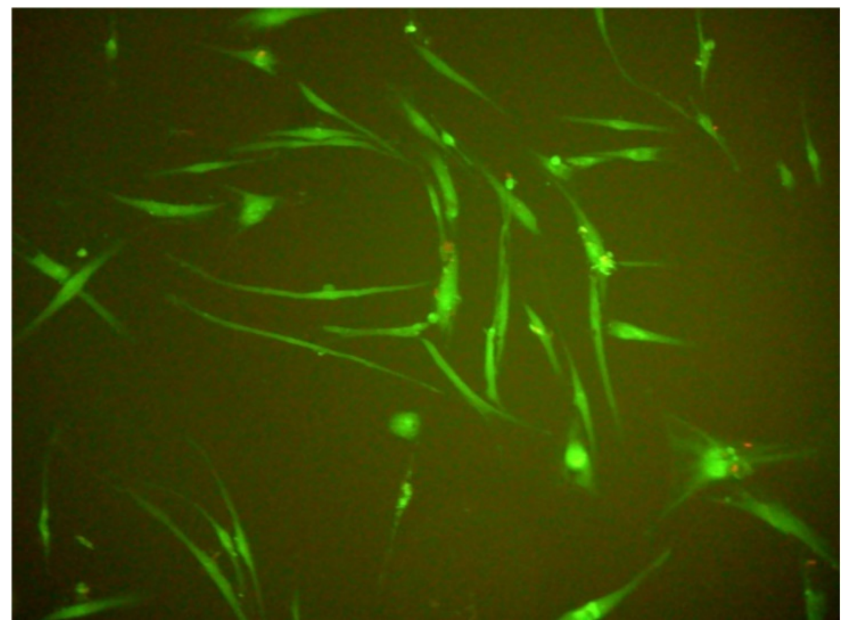

Figure 4. Human gingival fibroblasts (HGF-1)-fluorescence test (live/dead; viability/cytotoxicity kit).

\section{Viability of gingival fibroblasts}

In all experiments $92-96 \%$ gingival fibroblasts were viable cells, indicating green fluorescence with the use of Live/Dead Viability/Cytotoxicity Kit (Figure 4). No significant differences were observed between the viability of fibroblasts in control cultures and in the presence of EPSs from S. mutans or selected oral lactobacilli $(\mathrm{p}>0.05)$. The results obtained at zero time and in next $6,12,18$ or 24 hours are shown in Figure 5 and 6.

\section{Discussion}

This work analyses the effect of EPSs from cariogenic bacteria - S. mutans and L. acidophilus on ATP levels in human gingival fibroblasts. EPSs produced by the bacteria allow the formation of dental plaque (cariogenic biofilm) and are recognized as an essential virulence factor associated with dental caries $[17,18,19]$. At the same time it is noted that dental plaque accumulation located at and below the gingival margins induces gingival inflammation [20, 21]. This process starts chronic periodontitis which, in the consequence, leads to the destruction of periodontium $[9,22]$. The studies presented in this paper were conducted with the use of human gingival fibroblasts which constitute the dominant cells of the periodontium connective tissue and ensure integrity of its structure [23, 24]. The cellular adenosine triphosphate (ATP) level represents a significant exponent of cell metabolic activity and viability [25]. In vitro tests indicated that proliferative activity of fibroblasts is induced by the extracellular ATP [26]. A decrease in cellular ATP production provides metabolic conditions leading to cell death by different mechanisms, including apoptosis, autophagy, or necrosis $[27,28]$. Several techniques are used to estimate ATP concentration in cells $[29,30]$. However, the bioluminescence method provides the most sensitive and specific measurement [31, 32]. It has already been well documented that the emitted light intensity is linearly related to the ATP concentration [33]. These data justify the use of the above method in this work. The research did not prove the effect of EPS from S. mutans on ATP production in gingival 


\section{Gingival fibroblasts viability in control cultures} and with EPS from $S$. mutans

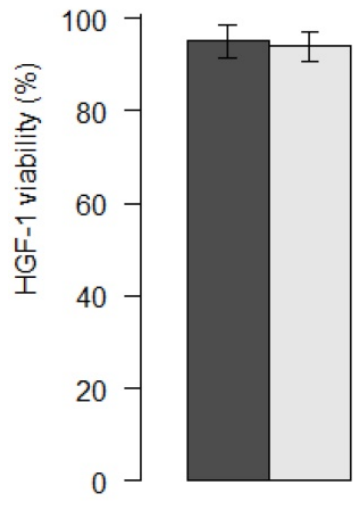

0

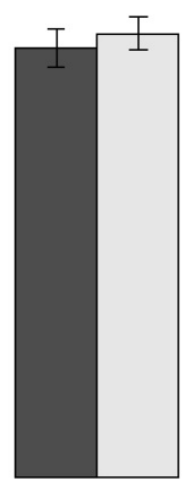

6

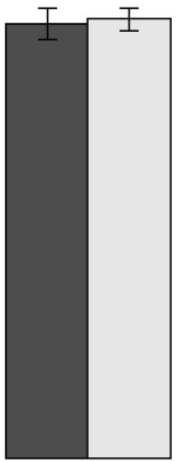

12

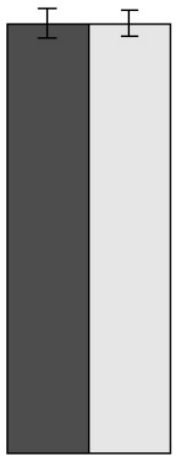

18

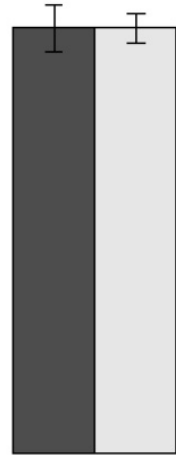

24

Incubation time $(\mathrm{h})$

\begin{tabular}{|c|c|c|c|c|c|c|c|c|c|c|}
\hline \multirow[b]{2}{*}{ time } & \multicolumn{5}{|c|}{ ㅁ HGF-1 (control) } & \multicolumn{5}{|c|}{$\square$ HGF-1 with EPS from $S$. mutans } \\
\hline & 0 & 6 & 12 & 18 & 24 & 0 & 6 & 12 & 18 & 24 \\
\hline mean & 95.0 & 93.0 & 94.0 & 93.0 & 92.0 & 94.0 & 96.0 & 95.0 & 93.0 & 92.0 \\
\hline sd & 3.4 & 4.1 & 3.5 & 3.2 & 5.1 & 3.2 & 3.5 & 2.5 & 2.9 & 3.2 \\
\hline
\end{tabular}

Figure 5. Gingival fibroblasts (HGF-1) viability (\%) in control cultures and with EPS from S. mutans at zero time and following 6, $12,18,24 \mathrm{~h}$ incubation.

fibroblasts. EPS secreted by $S$. mutans constitute monosaccharides, mainly a-D-glucans, which play a key role in the formation of dental plaque, mediating in cariogenic effect [34]. It is already known that oral streptococci, including S. mutans, may colonize both dental enamel and oral cells. There was also proven the importance of $S$. mutans biofilm in promoting these bacteria for adherence and invasion of human gingival cells [35]. However, there is no data presenting direct toxic effect of secreted EPS (a-D-glucan) from S. mutans on cells, which was not demonstrated in this work, either. Our results show that EPS (a-D-glucan) S. mutans does not affect the metabolic activity of gingival fibroblasts. Cytotoxicity of EPSs both from S. mutans, and from L. acidophilus towards fibroblasts was not demonstrated, either. Their viability in all cultures was not significantly different. On the other hand the relationship between dental plaque and destruction of periodontal tissues has already been well-documented [21, 22]. The earliest pathological changes associated with the development of dental plaque and its location at the gingival margin existing in gingival tissue may be the result of direct microbial action through their secreted products, or indirect action, in the result of bacterial induction of inflammatory response [36]. However, considering the data presented in this work, a conclusion can be drawn that a-D-glucan is not a direct factor destructing gingival tissues, so per se it does not play a role in initiating periodontal disease.

Whereas, EPSs from L. acidophilus isolates, irrespective of their ability to secrete $\mathrm{H}_{2} \mathrm{O}_{2}$, significantly increased ATP levels in gingival fibroblasts, which is demonstrated in this work for the first time. This effect may be caused by $\beta$-D-glucans which, as it has been documented, are the constituents of EPSs produced by some strains of L. acidophilus [37, $38]$. At the same time, $\beta$-D-glucans are considered as biological response modifiers [38, 39, 40]. Biological effects of $\beta$-D-glucans are influenced by their degree of branching, chain length, and tertiary structured [41]. It has been well-documented that EPS derived from L. rhamnosus KL37 demonstrates antiinflammatory potential. The recent research show, that the above EPS may control $\mathrm{T}$ lymphocytes activity in various inflammatory diseases [42]. It was also demonstrated that immunoregulatory properties of EPSs from Lactobacillus are strongly strain specific $[43,44]$. The results obtained in this work are consistent with our prior observations [12] and correspond to other data indicating that EPSs from some lactobacilli may protect human cells $[38,40]$. In the context of the above, it may by suggested that by promoting ATP synthesis in gingival fibroblasts EPSs from selected $L$. acidophilus strains stimulate their activity and process repairing. So, it seems likely that EPSs from selected strains of oral lactobacilli may limit the development of periodontitis.

At the same time, the diversity of L. acidophilus strains determined by the ability to secrete $\mathrm{H}_{2} \mathrm{O}_{2}$, which may be of particular significance in the pathogenesis of dental caries and periodontitis, is well-known $[45,46]$. In this work, the effect on EPSs fibroblasts deriving from two different strains of $L$. 


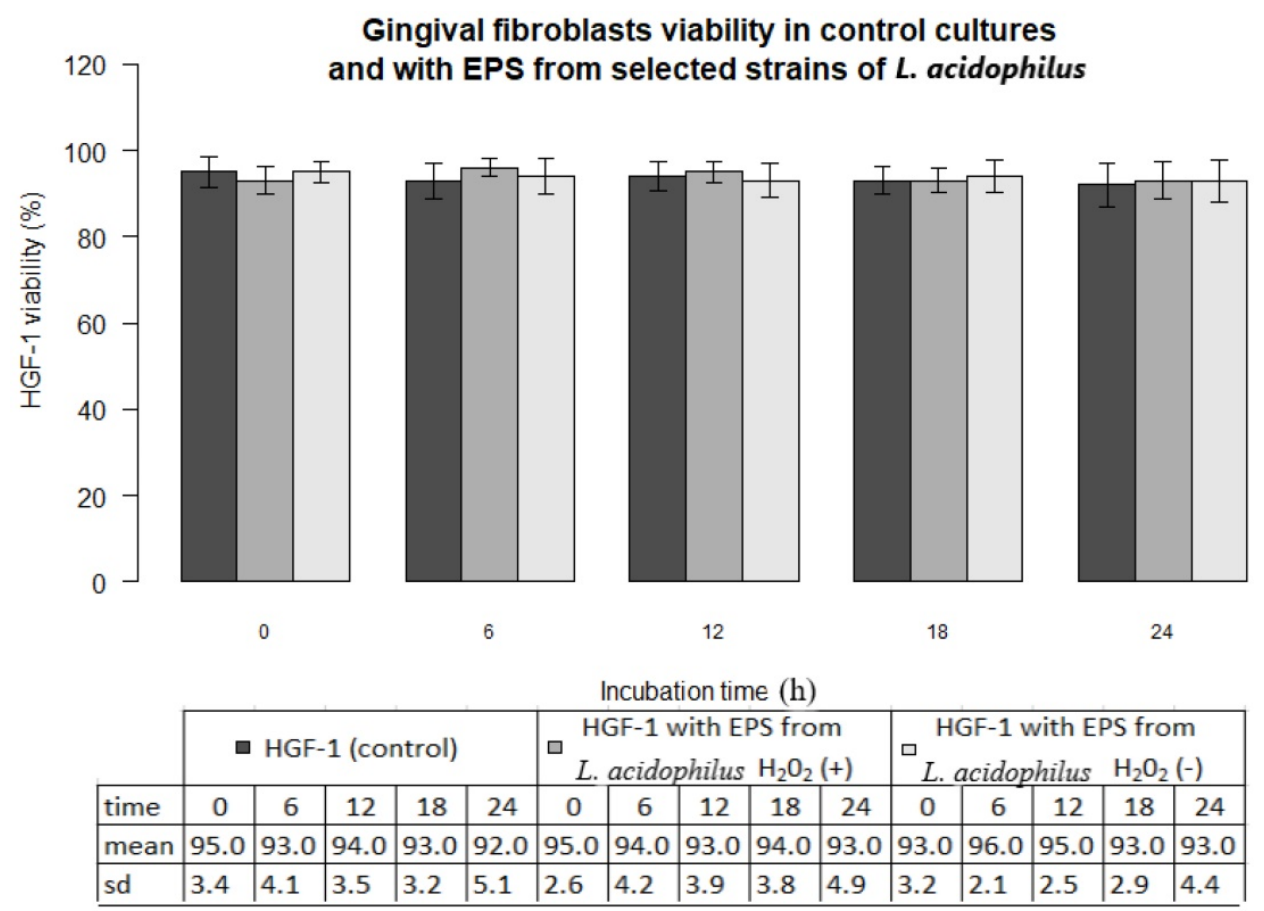

Figure 6. Gingival fibroblasts (HGF-1) viability (\%) in control cultures and with EPS from from L. acidophilus $\mathrm{H}_{2} \mathrm{O}_{2}(+)$ or L.acidophilus $\mathrm{H}_{2} \mathrm{O}_{2}(-)$ at zero time and following 6, 12 , $18,24 \mathrm{~h}$ incubation.

acidophilus $\left(\mathrm{H}_{2} \mathrm{O}_{2}\right.$-producing and $\mathrm{H}_{2} \mathrm{O}_{2}$-not producing) was not different, and did not confirm the strain specific activity of EPS. In the context of the above data it may be assumed that EPSs of both strains of one species have the same structure determining the same properties. So the tests prove that bacterial EPS is mainly species specific. However, strain specificity of EPS is also possible, which is determined by the synthesis of its altered structure among some strains of the same species.

In conclusion, the data obtained in this work demonstrated that EPS from $S$. mutans does not cause changes in ATP levels in HGF-1 and does not affect their viability, therefore it cannot constitute per se a pathogenic factor in initiating gingivitis associated with dental plaque. Whereas, EPSs deriving from some strains of oral lactobacilli cause an increase of ATP production in fibroblasts and therefore stimulate their activity which may demonstrate protective effect towards those cells.

\section{Acknowledgements}

The authors wish to thank Professor Tadeusz Malinski - Head of Biochemistry Research Laboratory, Ohio University, Athens, USA for facilitating the studies and giving valuable methodological guidelines.

\section{Funding}

Support for this research came from the Ita Pluta Plutowski endowment fund, the Ohio University
Foundation, and the Marvin and Ann Dilley White Professorship endowment.

\section{Author Contributions}

AS-K conducted the experiments, analyzed the data and wrote the manuscript. AS revised the manuscript. Both authors read and approved the final version of the manuscript.

\section{Competing Interests}

The authors have declared that no competing interest exists.

\section{References}

1. Selwitz RH, Ismail AI, Pitts NB. Dental caries. Lancet 2007; 369: 51-59.

2. Simón-Soro A, Mira A. Solving the etiology of dental caries. Trends Microbiol. 2015; 23: 76-82.

3. Pitts NB, Zero DT, Marsh PD, Ekstrand K, Weintraub JA, Ramos-Gomez F, et al. Dental caries. Nat Rev Dis Primers 2017; 3:17030.

4. Aas JA, Griffen AL, Dardis SR, Lee AM, Olsen I, Dewhirst FE, et al. Bacteria of dental caries in primary and permanent teeth in children and young adults. J Clin Microbiol. 2008; 46:1407-1417.

5. Bowen WH, Koo H. Biology of Streptococcus mutans-derived glucosyltransferases: role in extracellular matrix formation of cariogenic biofilms. Caries Res. 2011; 45: 69-86.

6. Krzyściak W, Jurczak A, Kościelniak D, Bystrowska B, Skalniak A. The virulence of Streptococcus mutans and the ability to form biofilms. Eur J Clin Microbiol Infect Dis. 2014; 33: 499-515.

7. Koo H, Falsetta ML, Klein MI. The exopolysaccharide matrix: a virulence determinant of cariogenic biofilm. J Dent. 2013; 92:1065-1073.

8. Klein MI, Hwang G, Santos PH, Campanella OH, Koo H. Streptococcus mutansderived extracellular matrix in cariogenic oral biofilms. Front Cell Infect Microbiol. 2015; 5:10

9. Pihlstrom BL, Michalowicz BS, Johnson NW. Periodontal diseases. Lancet 2005; 366:1809-1820.

10. Haffajee AD, Socransky SS, Patel MR, Song X. Microbial complexes in supragingival plaque. Oral Microbiol Immunol. 2008; 23: 196-205.

11. Kim YC, Ko Y, Hong SD, Kim KY, Lee YH, Chae C, et al. Presence of Porphyromonas gingivalis and plasma cell dominance in gingival tissues with periodontitis. Oral Dis. 2010; 16 : 375-381. 
12. Szkaradkiewicz AK, Karpinski TM, Zeidler A, Szkaradkiewicz A. Opposite effect of supernatants from selected periopathogens and oral lactobacilli cultures on ATP levels in human gingival fibroblasts. New Microbiol. 2014; 37: 509-516.

13. Rabe LK, Hillier SL. Optimization of media for detection of hydrogen peroxide production by Lactobacillus species. J Clin Microbiol. 2003; 41: 3260-3264.

14. van Geel-Schutten G, Flesch F, ten Brink B, Smith MR, Dijkhuizen L. Screening and characterization of Lactobacillus strains producing large amounts of exopolysaccharides. Appl Microbiol Biotechnol. 1998; 50: 697-703.

15. Rühmann B, Schmid J, Sieber V. Methods to identify the unexplored diversity of microbial exopolysaccharides. Front Microbiol. 2015; 6:565.

16. Masuko T, Minami A, Iwasaki N, Majima T, Nishimura S, Lee YC. Carbohydrate analysis by a phenol-sulfuric acid method in microplate format. Anal Biochem. 2005; 339: 69-72.

17. Marsh PD, Moter A, Devine DA. Dental plaque biofilms: communities, conflict and control. Periodontol 2000 2011; 55: 16-35.

18. Figuero E, Nóbrega DF, García-Gargallo M, Tenuta LM, Herrera D, Carvalho JC. Mechanical and chemical plaque control in the simultaneous management of gingivitis and caries: a systematic review. J Clin Periodontol. 2017; 44 (Suppl 18): S116-S134.

19. Lang NP, Bartold PM: Periodontal health. J Clin Periodontol. 2018; 45 (Suppl 20): S9-S16.

20. Mariotti A: Dental plaque-induced gingival diseases. Ann Periodontol. 1999; 4: 7-19.

21. Lang NP, Schätzle MA, Löe H: Gingivitis as a risk factor in periodontal disease. J Clin Periodontol. 2009; 36 (Suppl 10): 3-8.

22. Murakami S, Mealey BL, Mariotti A, Chapple ILC. Dental plaque-induced gingival conditions. J Clin Periodontol. 2018; 20 (Suppl 45): S17- S27.

23. Schroeder HE, Listgarten MA. The gingival tissues: the architecture of periodontal protection. Periodontol 2000 1997; 13: 91-120.

24. Ara T, Kurata K, Hirai K, Uchihashi T, Uematsu T, Imamura Y, et al. Human gingival fibroblasts are critical in sustaining inflammation in periodontal disease. J Periodontal Res. 2009; 44: 21-27.

25. Dietrich MO, Horvath TL. The role of mitochondrial uncoupling proteins in lifespan. Pflugers Arch. 2010; 459: 269-275.

26. Gerasimovskaya EV, Tucker DA, Weiser-Evans M, Wenzlau JM, Klemm DJ, Banks $M$, et al. Extracellular ATP-induced proliferation of adventitial fibroblasts requires phosphoinositide 3-kinase, Akt, mammalian target of rapamycin, and p70 S6 kinase signaling pathways. J Biol Chem. 2005; 280:1838-1848.

27. Lemasters JJ, Qian T, He L, Kim JS, Elmore SP, Cascio WE, et al. Role of mitochondrial inner membrane permeabilization in necrotic cell death, apoptosis, and autophagy. Antioxid Redox Signal. 2002; 4: 769-81.

28. Skulachev VP. Bioenergetic aspects of apoptosis, necrosis and mitoptosis. Apoptosis 2006; 11: 473-485.

29. de Korte D, Haverkort WA, van Gennip AH, Roos D. Nucleotide profiles of normal human blood cells determined by high-performance liquid chromatography. Anal Biochem. 1985; 147:197-209.

30. Lundin A, Hasenson M, Persson J, Pousette A. Estimation of biomass in growing cell lines by adenosine triphosphate assay. Methods Enzymol. 1986; 133: $27-42$.

31. Higashi T, Isomoto A, Tyuma I, Kakishita E, Uomoto M, Nagai K. Quantitative and continuous analysis of ATP release from blood platelets with firefly luciferase luminescence. Thromb Haemost. 1985; 53: 65-69.

32. Weyermann J, Lochmann D, Zimmer A. A practical note on the use of cytotoxicity assays. Int J Pharm. 2005; 288: 369-376.

33. Crouch SP. Biocompatibility testing using ATP bioluminescence. Med Device Technol. 2000; 11: 12-15.

34. Cugini C, Shanmugam M, Landge N, Ramasubbu N. The Role of exopolysaccharides in oral biofilms. J Dent Res. 2019; 98: 739-745.

35. Berlutti F, Catizone A, Ricci G, Frioni A, Natalizi T, Valenti P, et al. Streptococcus mutans and Streptococcus sobrinus are able to adhere and invade human gingival fibroblast cell line. Int J Immunopathol Pharmacol. 2010; 23: 1253-1260.

36. Löe $\mathrm{H}$, Theilade E, Jensen SB: Experimental gingivitis in man. J Periodontol. 1965; 36: 177-187.

37. Duenas-Chasco MT, Rodriguez-Carvajal MA, Tejero-Mateo P, Espartero JL, Irastorza-Iribas A, Gil-Serrano AM. Structural analysis of the exopolysaccharides produced by Lactobacillus spp. G-77. Carbohyd Res.1998; 307:125-133

38. Zannini E, Waters DM, Coffey A, Arendt EK. Production, properties, and industrial food application of lactic acid bacteria-derived exopolysaccharides. Appl Microbiol Biotechnol. 2016; 100: 1121-1135.

39. Sletmoen $M$, Stokke BT. Higher order structure of $(1,3)-\beta$-d-glucans and its influence on their biological activities and complexation abilities. Biopolymers 2008; 89: 310-321.

40. Patel S, Majumder A, Goyal A. Potentials of exopolysaccharides from lactic acid bacteria. Indian J Microbiol. 2012; 52: 3-12.

41. Zhang G, Li X, Xu X, Zeng F. Correlation between antitumor activity, molecular weight, and conformation of lentinan. Carbohyd Res.2005; 340: 1515-1521.

42. Nowak B, Śróttek M, Ciszek-Lenda M, Skałkowska A, Gamian A, Górska S, et al. Exopolysaccharide from Lactobacillus rhamnosus KL37 inhibits T Celldependent Immune Response in Mice. Arch Immunol Ther Exp. 2020; 68:17.
43. Ciszek-Lenda M, Strus S, Górska-Frączek S, Targosz-Korecka M, Śróttek M, Heczko P, et al. Strain specific immunostimulatory potential of lactobacilliderived exopolysaccharides. Central-European Journal of Immunology 2011; 3: 121-129.

44. Górska S, Sandstrőm C, Wojas-Turek J, Rossowska J, Pajtasz-Piasecka E, Brzozowska E, et al. Structural and immunomodulatory differences among lactobacilli exopolysaccharides isolated from intestines of mice with experimentally induced inflammatory bowel disease. Sci Rep. 2016; 6:37613.

45. Szkaradkiewicz A, Stopa J. Lactobacillus spp. of oral cavity microflora in pathogenesis of dental caries. Pol J Environ Stud. 2007; 16: 114-116,.

46. Szkaradkiewicz AK, Karpinski TM, Zeidler A, Wyganowska-Swiatkowska M, Szkaradkiewicz A. Protective effect of oral Lactobacilli in pathogenesis of chronic periodontitis. J Physiol Pharmacol. 2011; 62: 685-689. 